\title{
Antioxidants of Maltease orange peel: comparative investigation of the efficiency of four extraction methods
}

\author{
Nouha M'hiri ${ }^{1,2}$, Ioannou Irina ${ }^{2}$, Paris Cédric ${ }^{2}$, Mohamed Ghoul $^{2}$, Nourhene Boudhrioua ${ }^{1} *$ \\ ${ }^{1}$ Laboratoire de Physiopathologies, Alimentation et Biomolécules, LR17ES03, Institut Supérieur de Biotechnologie de Sidi Thabet, Université de la \\ Manouba, BP-66, 2020 Ariana, Tunis, Tunisie. ${ }^{2}$ Laboratory Reactions and Process Engineering, ENSAIA, Lorraine University, 2 avenue de la Forêt de \\ Haye, TSA 40602 Vandoeuvre Cedex 54518, France.
}

\begin{tabular}{|c|c|}
\hline ARTICLE INFO & ABSTRACT \\
\hline Article history: & \multirow{11}{*}{$\begin{array}{l}\text { The effect of four extraction methods applied at } 35^{\circ} \mathrm{C} \text { (conventional solvent extraction, CSE, ultrasound assisted } \\
\text { extraction, UAE, microwave assisted extraction, } \mathrm{MAE} \text { and supercritical } \mathrm{CO}_{2} \text { extraction, } \mathrm{SC}-\mathrm{CO}_{2} \text { ) on the total } \\
\text { phenol contents, total flavonoid contents, individual flavonoids, vitamin } \mathrm{C} \text { and antioxidant activity of orange } \\
\text { peel was examined. Neohesperidin (from } 0.624 \pm 0.013 \text { for } \mathrm{SC}-\mathrm{CO}_{2} \text { extraction to } 1.045 \pm 0.001 \mathrm{~g} / 100 \mathrm{~g} \text { orange peel } \\
\text { powder for MAE) and hesperidin (from } 0.407 \pm 0.008 \text { for } \mathrm{SC}-\mathrm{CO}_{2} \text { extraction to } 0.836 \pm 0.029 \mathrm{~g} / 100 \mathrm{~g} \text { orange peel } \\
\text { powder for UAE) are the major flavonoids }(80 \% \text { of total flavonoids by } \mathrm{MAE} \text { and } 87 \% \text { by CSE) of orange peel } \\
\text { whatever the used extraction method. The method giving the highest total phenol and flavonoid contents is } \\
\text { microwave assisted extraction ( } 2.363 \pm 0.014 \mathrm{~g} \mathrm{GAE} / 100 \mathrm{~g} \text { orange peel powder), followed by ultrasound assisted } \\
\text { extraction, conventional solvent extraction, and supercritical } \mathrm{CO}_{2} \text { extraction. However, vitamin C content is not } \\
\text { affected by the extraction method. Antioxidant activity (DPPH method) cannot be correlated to TPC, TFC or } \\
\text { individual flavonoids. Orange peel extracted by CSE presents the highest radical scavenging capacity compared } \\
\text { to the other extracts obtained by MAE, UAE and SC-CO } \mathrm{CO}_{2} \text { extraction. Besides, no additivity on the antioxidant } \\
\text { activity is found with the DPPH method. }\end{array}$} \\
\hline Received on: $14 / 12 / 2016$ & \\
\hline Accepted on: 11/03/2017 & \\
\hline Available online: $30 / 11 / 2017$ & \\
\hline Key words: & \\
\hline Orange peel, phenolic & \\
\hline compounds, vitamin $\mathrm{C}$, & \\
\hline & \\
\hline & \\
\hline & \\
\hline & \\
\hline
\end{tabular}

\section{INTRODUCTION}

Free radicals are atoms or group of atoms that have one or more unpaired electrons (Konan et al., 2016). The excessive production of these molecules induces the oxidative stress which leads to the appearance of many diseases such as diabetes, cancer, hypertension, and neurodegenerative diseases (Bairy et al., 2016). The human body produces natural antioxidants, like superoxide, catalase, peroxidase-glutathione system, which neutralize and inactive the free radicals, but, its remains not enough (Rao et al., 2006). Consequently, it is necessary to supply human body with a low cost source of natural antioxidants. Citrus byproduct presents rich sources of antioxidants, especially, polyphenols. Total phenol contents of the citrus peel varied

\footnotetext{
* Corresponding Author

Nourhene Boudhrioua, Laboratoire de Physiopathologies, Alimentation et Biomolécules, LR17ESO3, Institut Supérieur de Biotechnologie de Sidi Thabet, Université de la Manouba, BP-66, 2020 Ariana, Tunis, Tunisie. E-mail: nourhene.boudhrioua @gmail.com
}

from 0.67 to $7.30 \mathrm{~g} / 100 \mathrm{~g}$ dry matter (DM) (M'hiri et al., 2014). Citrus peel can be used in functional foods, pharmaceutical products formulations as an ingredient for preparation of antidiarrheal and detoxifying drugs(Liu et al., 2003; Piriyaprasarth et al., 2011) and also as a dietary supplement for human or animal feed (Bampidis and Robinson, 2006). Phenolic compounds of citrus peel exert numerous pharmacologically effects ranging from antioxidant to antiproliferative (Bocco et al., 1998; Ghasemi et al., 2009; Berim and Gang, 2015).

In fact, Xu et al. (2014) showed that polymethoxylaed flavones (PMF) of citrus reticulata extract (tangeretin and nobiletin), are the active components against the respiratory syncytial virus. In addition, the PMF of citrus can be used as nutraceutical supplement or as a therapeutic agent in pre-diabetic and metabolic syndrome conditions (Berim and Gang, 2015). Hespridin and naringin, major phenolic compounds of citrus byproduct, exhibit antidiabetic effect by potentiating the antioxidant defense system and suppressing pro-inflammatory 
cytokine production (Mahmoud et al., 2012 ; Park et al., 2013; Costantin et al., 2014; Vinayagam and $\mathrm{Xu}, 2015)$. Studies showed also that PMF of citrus byproduct inhibit the growth of cancer cell types and also responsible of for the anti-inflammatory effect (Saito et al., 2015; Wang et al., 2014; Berim and Gang, 2015).

Antioxidants extraction constitutes a difficult step because of their sensitivity to extraction conditions such as temperature, light or food matrix, which could lead to their degradation and alteration of their antioxidant activities (Ioannou et al., 2012). There are several methods of extraction of phenolic compounds in citrus peel as conventional solvent extraction (Manthey and Grohmann, 1996, Li et al., 2006). These methods can cause degradation of antioxidants due to the high temperature and the extraction time. Some other methods were used to increase the efficiency of the extraction such as microwave assisted extraction, ultrasound assisted extraction, high pressure extraction and supercritical fluid extraction or subcritical water (Chemat et al., 2009; Rawson et al., 2011). Some authors suggest a sequential use of two processes such as instant controlled pressure drop technology and ultrasound-assisted extraction (DIC-UAE) or combined approaches like enzyme assisted extraction in order to intensify the extraction operation and to enhance the extraction kinetic and yield (M'hiri et al., 2014). Boukroufa et al. (2015) combine ultrasound and microwave techniques to extract phenolics from orange peel waste, using only recycled water as solvent.

This concept allowed also the recuperation of essential oils and pectin. Some comparisons of the efficiency of different extraction methods were carried out in the literature but they are incomplete because only two or three methods were compared in the same work and this comparison only covers the extraction efficiency (Hayat et al., 2009; Khan et al., 2010). A study taking into account both the efficiency of extraction and preservation of phenolics activities should help to choose the appropriate extraction method. So, the purpose of this paper is to compare the performance of conventional solvent extraction (CSE), ultrasound assisted extraction (UAE), microwave assisted extraction (MAE), and supercritical $\mathrm{CO}_{2}$ extraction $\left(\mathrm{SC}-\mathrm{CO}_{2}\right)$ performed at soft condition $\left(35^{\circ} \mathrm{C}\right)$ on the selectivity, the total phenol contents, the total and individual flavonoids and the radical scavenging capacity of Maltease orange peel.

\section{MATERIAL AND METHODS}

\section{Plant material and sample preparation}

About $20 \mathrm{~kg}$ of fresh oranges (Citrus sinensis) of the Maltease cultivar were collected in March 2012 from Manzel Bouzalfa (Nabeul, Tunisia) at their commercial maturity. All fruits were of eating quality and without blemishes or damage. On arrival at the laboratory, the orange fruits were immediately washed using tap water and peeled. The remaining orange peel accounts for approximately $40 \%$ of the total fruit. The peels were stored at $-80^{\circ} \mathrm{C}$ before any further treatments. They were then dehydrated by using a freeze dryer (CHRIST Alpha 1-2 LD, France) for $72 \mathrm{~h}$ (at $-50^{\circ} \mathrm{C}$ and $0.001 \mathrm{mbar}$ ), then finely ground using a coffee grinder (Moulinex ${ }^{\circledR}$, France) and sieving to achieve a standard size of particles of $\sim 0.315 \mathrm{~mm}$. The orange peel powder was placed in vacuum packaging bags and stored in a freezer maintained at $-18^{\circ} \mathrm{C}$ before the experiments.

\section{Chemicals and reagents}

All chemicals used in the experiments carried out during this work are shown in Table 1. All chemicals were of analytical or HPLC grade purity.

\section{Extraction methods}

Conventional solvent extraction (CSE), ultrasound assisted extraction (UAE), microwave assisted extraction (MAE), and supercritical $\mathrm{CO}_{2}$ extraction $\left(\mathrm{SC}-\mathrm{CO}_{2}\right)$ methods were used. For the four phenol extraction methods, the temperature was set at $35^{\circ} \mathrm{C}$ to prevent thermal degradation of antioxidant molecules and carried out at darkness. The parameters of extraction methods were summarized in Table 2 . The crude extract provided by each technique was cooled at room temperature, centrifuged at $8000 \mathrm{~g}$ for $10 \mathrm{~min}$ and the supernatant was filtered through a Millipore paper $(0.22 \mu \mathrm{m})$. The residue was further extracted two times with $50 \mathrm{ml}$ of the same solvent under the same extraction conditions. A combination of the three extracts was collected and stored at $4{ }^{\circ} \mathrm{C}$.

Table 1: Chemicals and reagents used in experiments.

\begin{tabular}{|c|c|c|}
\hline Product & Provider & Purity $(\%)$ \\
\hline $\begin{array}{l}\text { Phenolics standards: eriocitrin, narirutin, naringin, hesperidin, neohesperidin, didymin, } \\
\text { sinensetin, tangeretin, nobiletin et } 3^{\prime}, 4^{\prime}, 5,5^{\prime} 6,7 \text {, hexamethoxyflavone }\end{array}$ & Extrasynthese (Lyon, France) & $\geq 95-99.0$ \\
\hline Potassium persulfate & Fluka (Switzerland) & \\
\hline Rutin & & $\geq 94.0$ \\
\hline Sodium nitrite $\left(\mathrm{NaNO}_{2}\right)$ & & $\geq 97$ \\
\hline Aluminium chloride $\left(\mathrm{AlCl}_{3}\right)$ & & 99.99 \\
\hline 2,2-diphenyl-1-picrylhydrazyl (DPPH) & & - \\
\hline 6-hydroxy-2,5,7,8-tetramethylchroman-2-carboxylic acid (Trolox) & & $\geq 97.0$ \\
\hline Folin-Ciocalteu's phenol reagent & Sigma-Aldrich (Germany) & - \\
\hline Sodium Carbonate $\left(\mathrm{Na}_{2} \mathrm{CO}_{3}\right)$ & & - \\
\hline Gallic acid monohydrate & & $\geq 98.0$ \\
\hline Ascorbic acid & & $\geq 99.0$ \\
\hline Hydrochloric acid & & - \\
\hline Sodium Hydroxide $(\mathrm{NaOH})$ & Carlo Erba-SDS (France) & - \\
\hline Methanol & Carlo Erba-sDs (France) & ـ \\
\hline Ethanol & VWR (Belgium) & $\geq 95.0$ \\
\hline Acetic acid & & $\geq 99.7$ \\
\hline
\end{tabular}


Table 2: Extraction conditions of CSE, UAE, MAE and $\mathrm{SC}-\mathrm{CO}_{2}$ methods.

\begin{tabular}{|c|c|c|}
\hline $\begin{array}{l}\text { Extraction } \\
\text { method }\end{array}$ & Conditions of extraction & Characteristics \\
\hline CSE & $\begin{array}{c}\text { Ethanol }(80 \%), \mathrm{m} / \mathrm{v}: 5 \mathrm{~g}: 50 \mathrm{ml}, 30 \mathrm{~min}, \mathbf{3 5}^{\circ} \mathbf{C} \text {, mechanical stirring at darkness, } 3 \\
\text { successive extractions. }\end{array}$ & - \\
\hline UAE & $\begin{array}{c}\text { Ethanol }(80 \%), \mathrm{m} / \mathrm{v}: 5 \mathrm{~g}: 50 \mathrm{ml}, 30 \mathrm{~min}, \mathbf{3 5}^{\circ} \mathbf{C}, \text { magnetic stirring at darkness, } 3 \\
\text { successive extractions, } \mathbf{1 2 5 W} \text {. }\end{array}$ & $\begin{array}{l}\text { Ultrasound sonicator (VibraCell 75115, Bioblock-Fisher, } \\
\text { Illkirch, France) }\end{array}$ \\
\hline MAE & Ethanol $(80 \%), \mathrm{m} / \mathrm{v}: 5 \mathrm{~g}: 50 \mathrm{ml}, \mathbf{1 0 s}, \mathbf{3 5}^{\circ} \mathbf{C}, \mathbf{1 7 0 W}, 3$ successive extractions. & Microwave oven (WAVEDOM LG, France) \\
\hline $\mathrm{SC}-\mathrm{CO}_{2}$ & Ethanol (80\%), m/v: 5g: 50ml, $30 \mathrm{~min}, \mathbf{3 5}^{\circ} \mathbf{C}, \mathbf{2 2} \mathbf{~ M P a}, 3$ successive extractions. & Pilot scale extractor (ENSIC, LRGP, Nancy, France) \\
\hline
\end{tabular}

\section{Analytical methods}

\section{Determination of total phenol and flavonoid contents $\left(T F C_{S P}\right.$,} $T P C_{F C}$ )

Total phenol contents were determined by FolinCiocalteu method, according to the method described by Singleton et al.(1988).The samples were added to Folin-Ciocalteu reagent and $\mathrm{Na}_{2} \mathrm{CO}_{3}$ solution and placed in a water bath at $40^{\circ} \mathrm{C}$ for 30 $\mathrm{min}$. Spectrophotometric analysis (spectrophotometer Genesys 10uv screening, Thermo Electron Corporation, France) was carried out at $765 \mathrm{~nm}$. Total phenols content determined by FolinCiocalteu method was designed as $\mathrm{TPC}_{\mathrm{FC}}$ and was expressed as $\mathrm{g}$ of gallic acid equivalent (GAE) per 100g orange peel powder.

Total flavonoid contents were determined by spectrophotometeric method, according to the modified procedure of Zhishen et al. (1999). $0.5 \mathrm{ml}$ of aqueous extract was placed in a $5 \mathrm{ml}$ volumetric flask, then $2.5 \mathrm{ml}$ of distilled water were added, followed by $0.15 \mathrm{ml}$ of $5 \% \mathrm{NaNO}_{2}$. After $5 \mathrm{~min}, 0.15 \mathrm{ml}$ of $10 \%$ $\mathrm{AlCl}_{3}$ were added. 5 min later, $1 \mathrm{ml}$ of $1 \mathrm{M} \mathrm{NaOH}$ were added and the volume made up with distilled water. The solution was mixed and absorbance was measured at $510 \mathrm{~nm}$ using a spectrophotometer (Genesys 10uv screening, Thermo Electron Corporation, France). Total flavonoid contents measured by spectrophotometeric method were designed as $\mathrm{TFC}_{\mathrm{SP}}$ and were expressed as rutin equivalent per $100 \mathrm{~g}$ orange peel powder.

\section{Determination of vitamin C contents}

Vitamin C content was titrated by a modified method described by Tabart et al.(2010) using dichlorophenol-indophenol 2,6 (DCPIP). $2 \mathrm{ml}$ of orange peel extract was added to $23 \mathrm{ml}$ of metaphosphoric acid solution $\left(\mathrm{HPO}_{3}\right) 5 \% .5 \mathrm{ml}$ was taken to which was added $5 \mathrm{ml}$ of a solution of trichloroacetic acid in $20 \% \mathrm{HPO}_{3}$. The solution obtained is then filtered and $2 \mathrm{ml}$ of the filtrate was mixed with $5 \mathrm{ml}$ of a buffer solution at $\mathrm{pH} 7.1$ and $1 \mathrm{ml}$ of 2,6 dichloro phenol indophenol (DCPIP). The absorbance was measured at $530 \mathrm{~nm}$. A standard range was performed using ascorbic acid at concentrations of $0,5,10,15,20 \mathrm{mg} / 1\left(\mathrm{R}_{2}=\right.$ 0.9995). The vitamin $\mathrm{C}$ content is expressed in $\mathrm{g}$ per $100 \mathrm{~g}$ of orange peel powder.

\section{Determination of radical scavenging activity}

The determination of the radical scavenging activity was realized for the four extracts obtained by the different extraction methods and the results were expressed as micromoles of Trolox equivalent for one micromole of phenolic compounds
(Rice-Evans et al., 1996). The free radical scavenging activities of orange peel extracts were determined by DPPH radical cation decolorization assay, according to the method of Burda and Oleszerk (2001). A $46.7 \mathrm{mg} / \mathrm{l}$ of 1.1-diphenyl-2-picrylhydrazyl (DPPH) was prepared by dilution of $11.7 \mathrm{mg}$ of DPPH with 250 $\mathrm{ml}$ of methanol incubated in dark. $80 \mu 1$ of sample extract was added to $220 \mu$ l of DPPH solution. The absorbance reading was taken at $25^{\circ} \mathrm{C}$, exactly $1 \mathrm{~min}$ after initial mixing $\left(\mathrm{OD}_{0}\right)$ and again at $30 \mathrm{~min}\left(\mathrm{OD}_{\mathrm{t}}\right)$. The control solution was prepared by adding $80 \mu \mathrm{l}$ of methanol to the DPPH solution and methanol was used as blank.

The inhibition percentage of absorbance at $515 \mathrm{~nm}$, using a spectrofluorometer (SAFAS flx Xenius, Monaco) was calculated between $\mathrm{OD}_{0}$ and $\mathrm{OD}_{\mathrm{t}}$, according to the following equation 1 . Appropriate solvent blanks were run in each assay.

$$
\text { Equation1: Percentageof inhibtion }=\frac{\left(O D_{0}-O D_{t}\right)}{O D_{0}} \times 100
$$

with $\mathrm{OD}_{0}$ as initial optical density and $\mathrm{OD}_{\mathrm{t}}$ as final optical density.

Then, Trolox equivalent antioxidant capacity (TEAC) was determined according to equation 2 .

$$
\text { Equation2: } T E A C=\frac{a_{S}}{a_{T}}
$$

$a_{\mathrm{S}}$ : line slope for sample of percentage of inhibition (\%) plotted $\mathrm{v} s$. concentration $(\mu \mathrm{M})$. $a_{T}$ : line slope for Trolox reference (6hydroxy-2,5,7,8-tetramethylchroman-2-carboxylic acid) of percentage of inhibition (\%) plotted $v s$. concentration $(\mu \mathrm{M})$.

\section{Additivity of antioxidant capacity}

To check the additivity of the antioxidant activity, a mixture containing the ten flavonoids identified in orange peel was prepared. The values obtained were compared to that predicted from the values of each compound corrected by their molar fraction (equation 3).

$$
\text { Equation3: TEACpredict }=\sum_{i=1}^{10} \prod \quad M i \times T E A C i
$$

Mi: molar fraction of each phenolic compound $i$

TEACi: Antioxidant activity of each phenolic compound i 


\section{Analysis of flavonoids by HPLC}

Identification of phenolic compounds in orange peel was carried out in two steps: identification by mass spectrometry and confirmation by HPLC analysis with the injection of standards by HPLC analysis with the injection of standards.

\section{Identification of phenolic compounds using HPLC-MS}

Qualitative analysis of orange peel phenolic compounds was performed using a HPLC-MS system (ThermoFisher Scientific, San Jose, CA, USA) equipped with an LTQ XL ion trap as mass analyzer (Linear Trap Quadripole). Chromatographic separation was performed on a C18 Alltima reverse phase column $(150 \times 2.1 \mathrm{~mm}, 5 \mu \mathrm{m}$ porosity - Grace/Alltech, Darmstadt, Germany) equipped with a C18 Alltima pre-column $(7.5 \times 2.1 \mathrm{~mm}$, $5 \mu \mathrm{m}$ porosity- Grace/Alltech) at $25^{\circ} \mathrm{C}$ and mobile phases consisted of water modified with formic acid $(0.1 \%)$ for $\mathrm{A}$, and methanol modified with formic acid $(0.1 \%)$ for B. Phenolics were eluted using a linear gradient from $10 \%$ to $100 \%$ of B in 78 min at

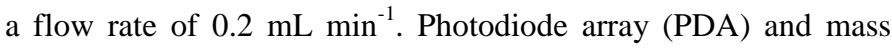
spectrometry (MS) detections were performed during the time of the run. The mass spectrometry operating parameters were set as follows: electrospray positive ionization mode $\left(\mathrm{ESI}^{+}\right)$was used; spray voltage was set at $5 \mathrm{kV}$; source gases were set (in arbitrary units $\mathrm{min}^{-1}$ ) for sheath gas, auxiliary gas and sweep gas at 40, 10 and 10 , respectively; capillary temperature was set at $300^{\circ} \mathrm{C}$; capillary voltage was set at $48 \mathrm{~V}$; tube lens, split lens and front lens voltages were set at $138 \mathrm{~V},-38 \mathrm{~V}$ and $-4.25 \mathrm{~V}$, respectively. The ion optic parameters were optimized by automatic tuning using a standard solution of rutin $\left(\mathrm{M}=610 \mathrm{~g} \cdot \mathrm{mol}^{-1}\right)$ at $0.1 \mathrm{~g} . \mathrm{L}^{-1}$ infused in the mobile phase (A/B: 50/50) at a flow rate of 5 $\mu$ L. min $^{-1}$. Full scan MS spectra were acquired from 100 to 2000 $\mathrm{m} / \mathrm{z}$.

\section{Analysis of flavonoids by HPLC}

Quantitative analysis of orange peel phenolic compounds was performed according to M'hiri et al. (2015)by using an HPLC analytical system (Elite LaChrom, VWR-Hitachi, France) consisting of a Spectra System P4000 pump, a Spectra System UV 6000LP diode array detector, a Spectra System SCM 1000 degasser and a Spectra System AS3000 auto-sampler controlled by software (THERMO CHROMQUEST).Total flavonoids content determined by calculation of the sum of individual flavonoids measured by HPLC was designed as $\mathrm{TFC}_{\mathrm{HPLC}}$ and was expressed as $\mathrm{g} / 100 \mathrm{~g}$ of orange peel powder.

\section{Statistical analysis}

All experiments were repeated 3 times; average and standard deviations were calculated. Statistical analysis was carried out using the software package IBM. SPSS 20.0 and the comparison of averages of each treatment were based on the analysis of variance (ANOVA) at significance level 5\%. Values followed by the same letter are not statistically significant according to Duncan's multiple range test at significance level $\mathrm{p}<$ 0.05. Principal component analysis (PCA) was performed on the correlation matrix of the measured parameters: $\mathrm{TF}_{\mathrm{HPLC}}$, sum of glycosylated flavanones (sum GF: neohesperidin, hesperidin, narirutin, naringin, didymin, eriocitrin), sum of polymethoxylated flavones (sum MF: sinensetin, tangeretin, nobiletin, hexamethoxyflavone) and TEAC. A measure of association between each measurement and the obtained principal components was provided.

\section{RESULTS AND DISCUSSION}

\section{Effect of extraction methods on total phenols and flavonoids content}

As reported in Figure 1, the $\mathrm{TPC}_{\mathrm{FC}}$ obtained by CSE was $1.968 \pm 0.003 \mathrm{~g} \mathrm{GAE} / 100 \mathrm{~g}$ of orange peel powder. This value is higher than that reported by Kammoun et al. (2011) for the same cultivar analyzed at its commercial ripening stage $(1.130 \pm 0.040$ gcaffeic acid/100 g DM). This difference can be due to used different extraction conditions. In fact, Kammoun et al. (2011) have applied a single extraction with filtration of the extract, evaporation of solvent and lyophilization of the residue. Whereas, in this study, three successive extractions were applied and were followed by filtration of the extract without evaporation or lyophilization of the residue. If total phenol contents were compared to that of other Citrus cultivars, significant variability could be noticed. In fact, the $\mathrm{TPC}_{\mathrm{FC}}$ of Maltease orange peel remains lower than that obtained by Ghanem et al. (2012) for fresh thompson peel $(1.899 \pm 0.012 \mathrm{~g}$ caffeic acid/100 g DM), Chen et al. (2011) (3.945 $\pm 0.100 \mathrm{~g}$ GAE/100g DM for Citrus Sinensis Osbeck peel and Ghasemi et al. (2009) (16.03 g GAE/100g of citrus peel powder for Citrus Sinensis Whashington, Navel variety). These differences can be attributed to many factors such as citrus cultivar and its stage of ripening, pedoclimatic factors (soil type, sun exposure, and rainfall), agronomic factors (biological culture, fruit yield per tree, and type of irrigation), and extraction methods used for phenolic analysis. The flavonoid content represents almost $50 \%$ of total phenolic of Maltease orange peel. This result was in accordance with these reported by Wang et al. (2011). Other studies mentioned that the total flavonoid contents can varied in a wide range: from $1.4 \%$ (Goulas et al., 2012) to $80 \%$ (Sultana et al., 2008). These variations can be explained by the interference of other compounds (sugars, organic acids like vitamin $\mathrm{C}$ ) on the Folin-Ciocalteu analysis(Neveu et al., 2010).

Figure 1 showed also that $\mathrm{TPC}_{\mathrm{FC}}(2.363 \pm 0.014 \mathrm{~g}$ $\mathrm{GAE} / 100 \mathrm{~g})$ and $\mathrm{TFC}_{\mathrm{SP}}(1.265 \pm 0.023$ grutin/100 g) provided by the MAE method were higher than those obtained by UAE followed by $\mathrm{CSE}$, and $\mathrm{SC}-\mathrm{CO}_{2}$ extraction method. Conventional solvent extraction gives low yield in comparison with UAE, and MAE. In fact, this method is accelerated by using ultrasound and microwave energy. The intensification of extraction efficiency using ultrasound has been attributed to the propagation of ultrasound pressure waves through the solvent and resulting cavitation phenomena (Rombaut et al., 2014). A cavitation bubble can be generated close to the plant material surface, then during a 
compression cycle, this bubble collapses and a microjet directed toward the plant matrix is created. The high pressure and temperature involved in this process will destroy the cell walls of the plant matrix and its content can be released into the medium. This phenomenon seems responsible for cell wall destruction and further release of the cellular content into the surrounding media (Chemat et al., 2011; Rombaut et al., 2014).

However, microwave irradiation accelerates the rupture of cells by causing a sudden temperature rise and internal pressure increase in the plant or fruit cell walls (Jawad and Langrish, 2012). During microwave processing, heating causes the disruption of weak hydrogen bonds caused by the dipole rotation of the molecules. A considerable amount of pressure builds up inside the biomaterial which modifies the physical properties of the biological tissues.

This modification improve the porosity of the biological matrix, allowing better penetration of extracting solvent through the matrix, and facilitating the collection of the phenolic compounds (Mandal et al., 2007). Besides, the increase of $\mathrm{TPC}_{\mathrm{FC}}$ in extract obtained by MAE can be explained by the breakdown of bigger phenolic compounds into smaller ones with their intact properties of the original molecules and which can react with Folin-Ciocalteu assay (Nayak et al., 2015a). In our study, Figure 1shows that vitamin $\mathrm{C}$ contents measured in the different extracts remain constant whatever the used extraction method. The preservation of vitamin $\mathrm{C}$ content could be attributed to the low temperature applied during extraction $\left(35^{\circ} \mathrm{C}\right)$.

Figure 1 indicates also that supercritical $\mathrm{CO}_{2}$ extraction method gives the lowest $\mathrm{TPC}_{\mathrm{FC}}$ and $\mathrm{TFC}_{\mathrm{SP}}(1.204 \pm 0.019 \mathrm{~g}$ GAE/100 g, 0.589 \pm 0.036 grutin/100 g respectively) compared to others methods. This result can be explained by the fact that orange peel is richer in polar flavonoids (flavanones) than nonpolar ones (polymethoxylated flavones), while supercritical $\mathrm{CO}_{2}$ extraction is more adapted to non-polar compounds(Diaaz-Reinoso et al., 2006; Pereira and Meireles, 2010).

Toledo-Guillen et al. (2010) reported that CSE is more efficient than $\mathrm{SC}-\mathrm{CO}_{2}$ for the extraction of glycosylated flavanones. This result is attributed to the high molecular weight and polarity of flavonoids.

According to total phenol content, the efficiency of the examined extraction methods of phenolic and flavonoid contents from citrus peel follows the decreasing order: microwave assisted extraction followed by ultrasound assisted extraction, conventional solvent extraction and supercritical $\mathrm{CO}_{2}$ extraction.

These results are in accordance with those found by others authors. Dahmoune et al. (2013) compared three methods of extraction of lemon peel phenolic compounds: CSE, UAE and MAE. The authors reported that ultrasound causes disruption of plant cells by cavitation. The particles of lemon peel powder are resistant to ultrasound energy (Aspé and Fernández, 2011). The rise of pressure in the cellular pores causes a faster break compared with the control. However, MAE causes more intense tissue degradation under the action of microwaves. Indeed, MAE dehydrates cellulose and reduces its mechanical strength, which allows an easy penetration of the solvent into the cellular channels (Mandal et al., 2007). Heating by microwave causes cellular damage and a weakened microstructure that helps to quickly release the solute in the solvent.

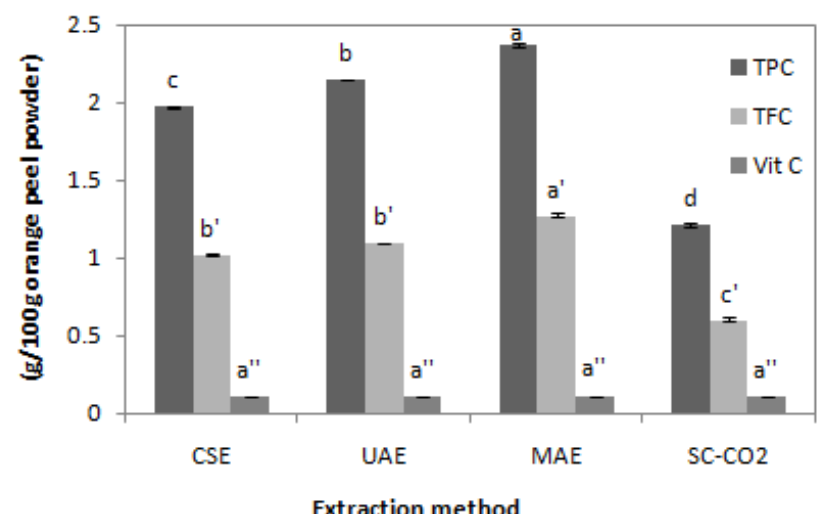

Fig. 1: $\mathrm{TPC}_{\mathrm{FC}}, \mathrm{TFC}_{\mathrm{SP}}$ and vitamin $\mathrm{C}$ content of Maltease orange peel obtained by CSE (conventional solvent extraction), UAE (ultrasound assisted extraction), MAE (microwave assisted extraction), and $\mathrm{SC}^{-} \mathrm{CO}_{2}$ (supercritical $\mathrm{CO}_{2}$ extraction) methods. Results are present as means \pm S.D. for triplicate analysis. Values with the same letter are not significantly different at $\mathrm{p}<0.05$.

\section{Identification and quantification of orange peel flavonoids in different extracts}

Ten phenolic compounds were identified in Maltease orange peel extracts. Results obtained by HPLC-DAD-MS were presented in Table 3.

These results showed that flavanones (eriocitrin, narirutin, naringin, hesperidin, neohesperidin, didymin) and polymethoxylated flavones (sinensetin, 3', 4', 5, 5'6, 7,Hexamethoxyflavone, tangeretin, nobiletin) are the main compounds of the ethanolic extract. Except for narirutin and eriocitrin, a similar composition was reported by Anagnostopoulou et al. (2005) in Greek Navel sweet orange peel. However, this variety also contains pentamethoxyflavone. Whereas, Kanaze et al. (2008) found in Navel orange peel five flavanones (hesperidin, neohesperidin, naringin, didymin), three glycosylated flavones (leuteolin-7- $O$-rutinoside, chrysoeriol-7- $O$-rutinoside, diosmin), polymethoxylated flavones (sinensetin, nobiletin, hexamethoxyflavoneheptamethoxyflavone). Moreover, ToledoGuillén et al. (2010) identified in orange peel extracts glycosylated flavanones (hesperidin, narirutin) and the polymethoxyflavones (sinensetin, nobiletin, tetramethylscutellarein and tangeretin).

The percentages of the ten identified flavonoids reported to total flavonoids content, $\mathrm{TFC}_{\mathrm{HPLC}}$ (corresponding to the sum of individual flavonoids determined by HPLC) are summarized table 4. The total phenol contents of Maltease orange peel extract (CSE) determined by the Folin test are equal to $1.968 \pm 0.003 \mathrm{~g} \mathrm{EAG} / 100$ $\mathrm{g}$ of orange peel powder, whereas, the sum of individual flavonoids determined by HPLC and cited previously (Table 4) is equal to $1.609 \mathrm{~g} / 100 \mathrm{~g}$ of orange peel powder. 
Table 3: $\mathrm{R}_{\mathrm{t}}$, pseudomolecular ions, adduct ions with $\mathrm{Na}^{+}$, and $\mathrm{UV}_{\max }$ of orange peel phenolic compounds identified by HPLC-DAD-MS. Conventional solvent extraction: $\mathrm{m} / \mathrm{v}: 5 \mathrm{~g}: 50 \mathrm{ml}, 30 \mathrm{~min}, 35^{\circ} \mathrm{C}$, ethanol $80 \%$, mechanical agitation at darkness and 3 extraction cycles.

\begin{tabular}{|c|c|c|c|c|c|}
\hline Order of appearance & $\begin{array}{c}\mathbf{R}_{\mathbf{t}} \\
(\mathbf{m i n})\end{array}$ & $\begin{array}{c}\mathbf{M + H}]^{+} \\
(\mathbf{m} / \mathbf{z})\end{array}$ & $\begin{array}{c}\mathbf{M}+\mathbf{N a}]^{+} \\
(\mathbf{m} / \mathbf{z})\end{array}$ & $\mathbf{U V} \boldsymbol{\lambda}_{\max }(\mathrm{nm})$ & Identification \\
\hline 1 & 22.80 & 597 & 619 & 284,327 & Eriocitrin \\
\hline 2 & 31.85 & 581 & 603 & 284,329 & Narirutin \\
\hline 3 & 31.97 & 581 & 603 & 280,328 & Naringin \\
\hline 4 & 33.10 & 611 & 633 & 284,328 & Hesperidin \\
\hline 5 & 33.95 & 611 & 633 & 285,327 & Neohesperidin \\
\hline 6 & 40.77 & 595 & 617 & $226,284,332$ & Didymin \\
\hline 7 & 51.58 & 373 & 395 & $240,264,328$ & Sinensetin \\
\hline 8 & 52.37 & 403 & 425 & $237,268,320$ & $3^{\prime}, 4^{\prime}, 5,5^{\prime} 6,7$, Hexamethoxyflavone \\
\hline 9 & 55.29 & 402 & 425 & $249,271,334$ & Nobiletin \\
\hline 10 & 58.54 & 372 & 395 & 271,324 & Tangeretin \\
\hline
\end{tabular}

Table 4: Contents of individual flavonoid compounds (as g/100g of orange peel powder) of Maltease orange peel extracted by CSE, UAE, MAE and SC-CO ${ }_{2}$.

\begin{tabular}{|c|c|c|c|c|}
\hline Compound & CSE & UAE & MAE & $\mathrm{SC}-\mathrm{CO}_{2}$ \\
\hline Hesperidin & $0.551 \pm 0.001^{\mathrm{c}}$ & $0.836 \pm 0.029^{a}$ & $0.781 \pm 0.074^{\mathrm{b}}$ & $0.407 \pm 0.008^{d}$ \\
\hline Neohesperidin & $0.860 \pm 0.003^{c}$ & $0.986 \pm 0.006^{\mathrm{b}}$ & $1.045 \pm 0.001^{\mathrm{a}}$ & $0.624 \pm 0.013^{\mathrm{d}}$ \\
\hline Eriocitrin & $0.019 \pm 0.001^{\mathrm{a}}$ & $0.019 \pm 0.001^{\mathrm{a}}$ & $0.016 \pm 0.000^{\mathrm{a}}$ & $0.007 \pm 0.001^{b}$ \\
\hline Narirutin & $0.038 \pm 0.001^{\mathrm{a}}$ & $0.017 \pm 0.001^{c}$ & $0.002 \pm 0.001^{\mathrm{e}}$ & $0.008 \pm 0.001^{\mathrm{d}}$ \\
\hline Naringin & $0.042 \pm 0.001^{\mathrm{c}}$ & $0.081 \pm 0.009^{b}$ & $0.218 \pm 0.001^{\mathrm{a}}$ & $0.043 \pm 0.005^{\mathrm{c}}$ \\
\hline Didymin & $0.026 \pm 0.001^{\mathrm{c}}$ & $0.041 \pm 0.003^{\mathrm{b}}$ & $0.062 \pm 0.001^{\mathrm{a}}$ & $0.018 \pm 0.001^{\mathrm{d}}$ \\
\hline Sinensetin & $0.020 \pm 0.001^{\mathrm{d}}$ & $0.040 \pm 0.002^{\mathrm{ab}}$ & $0.040 \pm 0.001^{\mathrm{b}}$ & $0.045 \pm 0.002^{\mathrm{a}}$ \\
\hline Hexamethoxyflavone & $0.006 \pm 0.001^{\mathrm{c}}$ & $0.010 \pm 0.013^{\mathrm{b}}$ & $0.016 \pm 0.002^{\mathrm{a}}$ & $0.010 \pm 0.006^{\mathrm{b}}$ \\
\hline Tangeretin & $0.005 \pm 0.001^{\mathrm{a}}$ & $0.009 \pm 0.003^{\mathrm{a}}$ & $0.011 \pm 0.000^{\mathrm{a}}$ & $0.008 \pm 0.001^{\mathrm{a}}$ \\
\hline Nobiletin & $0.042 \pm 0.002^{\mathrm{e}}$ & $0.074 \pm 0.003^{b}$ & $0.084 \pm 0.001^{\mathrm{a}}$ & $0.068 \pm 0.001^{\mathrm{c}}$ \\
\hline $\mathrm{TFC}_{\mathrm{HPLC}}$ & $1.609 \pm 0.013^{\mathrm{b}}$ & $2.113 \pm 0.017^{\mathrm{a}}$ & $2.275 \pm 0.082^{\mathrm{a}}$ & $1.238 \pm 0.090^{\mathrm{c}}$ \\
\hline
\end{tabular}

CSE: conventional solvent extraction, UAE: ultrasound assisted extraction, MAE: microwave assisted extraction, and $\mathrm{SC}-\mathrm{CO}_{2}$ : supercritical $\mathrm{CO}_{2}$ extraction.

Results are presented as means \pm S.D. for triplicate analysis. Values with the same letter are not significantly different at $\mathrm{p}<0.05$.

This difference $(\sim 18.2 \%)$ between spectrophotemtric and chromatographic methods was acceptable and it can be explained by the fact that the Folin test overestimate the content of total phenols due to interference of the reagent with other reducing compounds which may exist in the extract (Singleton et al., 1988) as reducing sugars (fructose, glucose etc.) and organic acids (vitamin $\mathrm{C}$, citric acid malonic acid etc.).

Furthermore, the content of total flavonoids determined by HPLC $(1.609 \mathrm{~g} / 100 \mathrm{~g}$ of orange peel powder) is higher than the total flavonoids content determined by spectrometric method $(1.012 \pm 0.003 \mathrm{~g} \mathrm{rutin} / 100 \mathrm{~g}$ of orange peel powder).

The spectrometric method of determination of total flavonoids underestimates the actual content of total flavonoids and this can be explained by the fact that some phenolic compounds cannot react with aluminum trichloride $\left(\mathrm{AlCl}_{3}\right)$ as hesperidin which is present in large quantities in the Maltease orange peel $(34.24 \%)$. The spectrophotemtric method was the main common method used by many authors for total flavonoid estimation and for comparison between process efficiency or variability between products (Sultana et al., 2008; Ghasemi et al., 2009). Chromatographic analysis remains more appropriate and thus should be recommended for phenols determination in citrus.

Table 4 shows the individual flavonoids content of citrus Maltease peel expressed as $g / 100 \mathrm{~g}$ orange peel powder. The results obtained indicate that the efficiency of the extraction for a given method depends upon the structure of the flavonoid. The highest quantities of neohesperidin, hesperidin, didymin, naringin, nnobiletin, tangeretin and hexamethoxyflavone were obtained respectively by using MAE. The eriocitrin content is achieved with a maximum content by UAE, $\mathrm{SC}-\mathrm{CO}_{2}$ (difference not significant) while it is $\mathrm{CSE}$ and $\mathrm{SC}-\mathrm{CO}_{2}$ for the highest levels of sinensetin and narirutin. This result coincides with those found in the literature. Indeed, Hayat et al. (2009) compared CSE, MAE and UAE for the extraction of phenolic acids from mandarin peel. The MAE provides the highest level of ferulic acid $(0.239 \mathrm{~g} / 100 \mathrm{~g} \mathrm{DM})$ compared to UAE $(0.235 \mathrm{~g} / 100 \mathrm{~g}$ DM) and CSE $(0.205 \mathrm{~g} / 100 \mathrm{~g}$ DM). Khan et al. (2010) reported that the contents of hesperidin and naringin of orange peel Valencia cultivar, obtained by UAE were significantly higher $(0.250$ and $0.070 \mathrm{~g} / 100 \mathrm{~g} \mathrm{DM}$, respectively) than those obtained by CSE $(0.145$ and $0.051 \mathrm{~g} / 100 \mathrm{~g}$ DM, respectively).

\section{Effect of extraction methods on radical scavenging activity}

As has been previously reported, the amount of total and individual flavonoids of orange peel extracts depend on the used method. This variation should affect the antioxidant activity of the different extracts. To evaluate this effect, the antioxidant activity was measured by DPPH method (Figure 2). Vitamin C contents were measured in the different extracts; it appears that this content remains constant $(200 \mu \mathrm{M})$ whatever the extraction used method. So the variations observed cannot be attributed to this molecule. These data show that orange peel extract obtained by CSE presents the highest radical scavenging capacity compared to extracts obtained by other extraction methods. Moreover, it can be noticed a significant decrease of the radical scavenging activity by the DPPH method in the following order: CSE, SC- $\mathrm{CO}_{2}, \mathrm{MAE}$ and UAE. These results are not in accordance with those previously reported for $\mathrm{TPC}_{\mathrm{FC}}$ and $\mathrm{TFC}_{\mathrm{SP}}$ (Figure 1). 


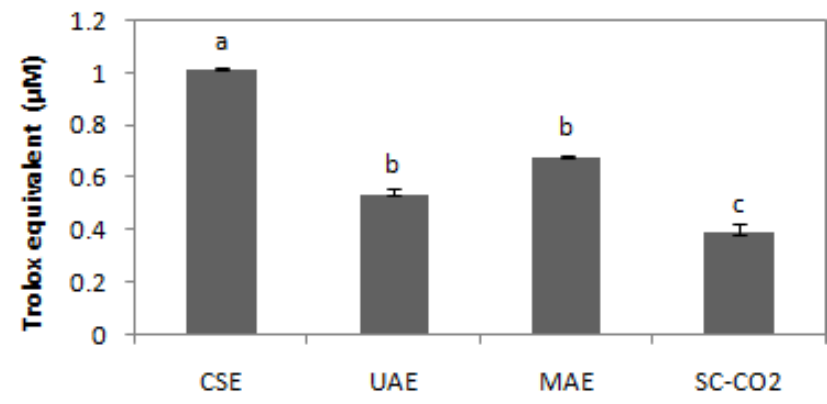

Extraction method

Fig. 2: Radical scavenging activity ( $\mu \mathrm{M}$ Trolox equivalent, DPPH test) measured for Maltease orange peel extracts obtained by CSE, UAE, MAE and $\mathrm{SC}-\mathrm{CO}_{2}$ methods.

Indeed, a decrease of $15.44 \%$ was observed for antioxidant activity of MAE extract compared to CSE although that MAE extract contains the highest phenolics content $\left(\mathrm{TPC}_{\mathrm{FC}}\right.$, $\mathrm{TFC}_{\mathrm{sp}}$ and $\mathrm{TFC}_{\mathrm{HPLC}}$ ). This result could be explained by (i) a slow reaction between citrus flavonoids with the stable DPPH and / or (ii) a different quantitative flavonoids composition of the extracts (Table 4), (iii) the appearance of new formed compounds during MAE and interactions between the different compounds, resulting in positive or negative synergies of antioxidant activity(Hidalgo et al., 2010). According to literature, compounds newly formed during the Maillard and thermo-oxidation reactions could be explained the increase of antioxidant activity of MAE extract. In our case, after the MAE, a change of extract color from orange to brown and an odor of caramelization were noticed, but we can't identify new compounds in HPLC chromatogram. The products of the Maillard reaction (PMR) could be divided into different groups. During the first phase of the PMR training, small molecules such as glyoxyl, methyloxyl and others are trained dicarbonyls (Hodge, 1953; Yaylayan and Haffenden, 2003). Since these compounds have a high oxidative potential and chemical activity, PRM trained at this stage tend to be pro-oxidant. The high chemical activity of these products between them, leads to higher molecular weight products and a brown color through a series of condensation and polymerization reaction (Nicoli et al., 1994). PMR complexes are at the later stage antioxidant and were named collectively melanoidins (Wagner et al., 2002; Liu et al., 2008). These compounds can interact during extraction to form other compounds that could present different structures and properties from the original (Gil-Chavez et al., 2013).

Figure 2 showed also that the radical scavenging activity of the extract obtained by UAE is lower than the CSE extract (29.27\%). This result is similar to that reported by Dahmoune et al. (2013). The authors have shown that the antioxidant activity of the lemon peel extract obtained by CSE is higher than that achieved by the UAE. This can be explained by the fact that ultrasound may induce the formation of free radicals in the liquid medium and improves the sonochemical reactions and polymerization/depolymerisation reactions, thus causing oxidation, degradation of bioactive compounds and appearance of offflavours of the products (Pingret et al., 2012; Pingret et al.,
2013; Nayak et al., 2015b). In conclusion, it must also be pointed out that the radical scavenging method (DDPH test) is not sufficient to evaluate the whole antioxidant activity of the extract because some flavonoids make a minor contribution in the DPPH assay. Therefore, it is necessary to apply others methods to explain the mechanisms by which the orange peel extracts acts as antioxidant such as ferric reducing-antioxidant power (FRAP) assay, hydroxyl radical scavenging activity, nitric oxide scavenging activity. Table 5 shows the antioxidant activity of the ten individual flavonoids of orange peel extract and the vitamin $\mathrm{C}$, measured by DPPH. These results indicate that the highest antioxidant activities were observed for neohesperidin, eriocitrin and vitamin $\mathrm{C}$ respectively with DPPH method. However, nobiletin, sinensetin and narirutin do not present any activity. The results were confirmed by Khan et al.(2010) who reported that the flavanones of orange peel react very slowly with the stable DPPH radical, making, therefore, a minor contribution. To check the assumption of negative or positive synergic effects of flavonoids on the antioxidant activity, the antioxidant activity of a mixture prepared from the ten flavonoids was compared to that predicted from the values of each compound corrected by their molar fraction (Table 5). The results showed that we have a clear synergic effect. Thus, a value of $0.100 \pm 0.013$ was obtained by DPPH against $0.332 \pm 0.001$ for the predicted one. These results coincide with those found by Hidalgo et al.(2010) which concluded that it is impossible to predict the antioxidant activity of a sample just by studying one type of flavonoid or other types of antioxidants in the extract such as vitamin $\mathrm{C}$ or vitamin $\mathrm{E}$. In some cases, synergistic or antagonistic effects may occur resulting in the increase or decrease in the total antioxidant activity of the extract (Reber et al., 2011).

Table 5: Antioxidant activity of individual flavonoids and vitamin $\mathrm{C}(\mu \mathrm{M}$ Trolox equivalent, DPPH test) of Maltease orange peel extract.

\begin{tabular}{cccc}
\hline Compound & $\begin{array}{c}\text { DPPH }(\boldsymbol{\mu M} \\
\text { Trolox })\end{array}$ & $\begin{array}{c}\text { Concentrat } \\
\text { ion in the } \\
\text { extract } \\
(\boldsymbol{\mu M})\end{array}$ \\
\hline Glycosylated & Neohesperidin & $0.095 \pm 0.012$ & 467 \\
flavanones & Hesperidin & $0.054 \pm 0.002$ & 300 \\
& Vitamin C & $1.224 \pm 0.027$ & 200 \\
& Eriocitrin & $1.009 \pm 0.012$ & 11 \\
& Narirutin & ND at 344 $\mu \mathrm{M}$ & 22 \\
Polymethoxylated & Didymin & $0.083 \pm 0.019$ & 15 \\
flavones & Naringin & $0.056 \pm 0.021$ & 24 \\
\hline & Texamethoxyflavone & $0.038 \pm 0.009$ & 5 \\
& Nobiletin & $0.115 \pm 0.022$ & 4 \\
& Sinensetin & ND at $1 \mu \mathrm{M}$ & 18 \\
\hline & TEAC predicted & $0.332 \pm 0.001$ & - \\
& (Equation 3) & $0.100 \pm 0.013$ & - \\
\hline & TEAC measured & (Equation 2) &
\end{tabular}

This study showed also that there isn't a correlation between radical scavenging activity (TEAC) and total flavonoids contents $\left(\mathrm{TF}_{\mathrm{HPLC}}\right)$ or glycosylated flavanones (sum GF) but significant negative correlation was observed for TEAC-and polymethoxylated flavones(Sum MF) (Table 6). This result is in 
agreement with those reported by Ghasemi et al. (2009). The authors explain the absence of correlation by the fact that flavonoids can act as proton donating and show radical scavenging activity, but, orange peel extract is a mix of compounds with distinct activities.

Table 6: Correlation matrix between variables.

\begin{tabular}{lcccc}
\hline Variables & TF $_{\text {HPLC }}$ & Sum GF & Sum MF & TEAC \\
\hline TF $_{\text {HPLC }}$ & 1.000 & 0.988 & 0.431 & 0.140 \\
Sum GF & 0.988 & 1.000 & 0.339 & 0.213 \\
Sum MF & 0.431 & 0.339 & 1.000 & $\mathbf{- 0 . 7 6 8}$ \\
TEAC & 0.140 & 0.213 & -0.768 & 1.000 \\
\hline
\end{tabular}

$\mathrm{TF}_{\text {HPLC: }}$ : sum of total flavonoids determined by HPLC, Sum GF: sum of glycosylated flavanones, Sum MF: sum of polymethoxylated flavones, TEAC: Trolox Equivalent Antioxidant Capacity.

\section{Comparison of the efficiency of the different extraction methods}

Results of PCA (Figure 3) revealed that $98.19 \%$ of the variation among the measured parameters $\left(\mathrm{TF}_{\mathrm{HPLC}}\right.$, SumGF, Sum MF, TEAC) was attributed to the first two principal components (Table 7).The first principal component $\left(\mathrm{TF}_{\mathrm{HPLC}}\right)$ explains $55.99 \%$ of the variance and the second component (Sum GF) explains $42.20 \%$ of the variance. Based on the PCA analysis, the four extraction methods could be gathered in three groups according to the first principal component $\left(\mathrm{TF}_{\mathrm{HPLC}}\right)$ and the second principal component (Sum GF). The first group was formed by CSE and the second group corresponds to $\mathrm{SC}-\mathrm{CO}_{2}$, whereas, the MAE and UAE could be gathered in one homogenous group. Our study showed that supercritical $\mathrm{CO}_{2}$ extraction gives the lowest flavonoids content compared with the others methods of extraction. This result can be explained by the non-polar characteristic of $\mathrm{CO}_{2}$, which limited its application for the extraction of polar compounds, which are the major phenolics of orange peel.

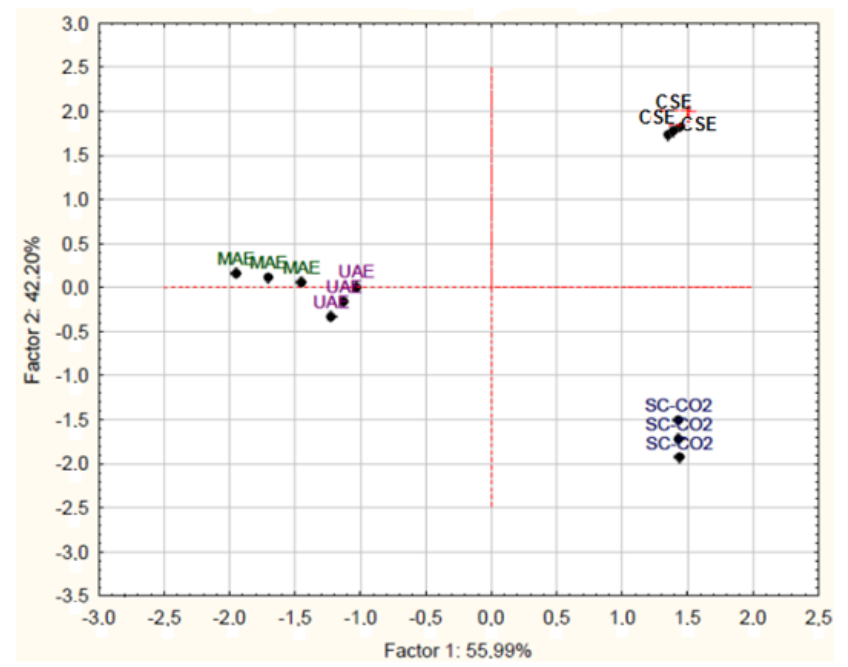

Fig. 3: Projection of the extraction methods on the factor plane according to the first principal component $\left(\mathrm{TF}_{\mathrm{HPLC}}\right)$ and the second principal component (Sum GF).

Both ultrasonic and microwave extraction methods gave the highest phenolic contents. Ultrasound assisted extraction allows the breakdown of plant cells, and the improvement of solvent penetration and capillary effects of ultrasound (Mason et al., 2011). Whereas, microwave assisted extraction showed obvious advantages in terms of high extraction efficiency within the shortest extraction time.

These results are in agreement with the findings of other researchers (Hayat et al., 2010; Jawad and Langrish, 2012). MAE can extract bioactive compounds more rapidly and a better recovery is possible than conventional extraction processes.

It isn't possible to conclude about a single extraction method based on determined antioxidant compounds and antioxidant activity. The choice of the extraction method varied according to the objective (total flavonoids, major compounds, antioxidant activity). For example, if the objective is to obtain the highest content of total flavonoids, MAE is the best extraction method. Whereas CSE allows obtaining the highest radical scavenging activity, compared to the others investigated methods.

Table 7: Eigen values of correlation matrix and related statistics.

\begin{tabular}{lcccc}
\hline Variables & $\begin{array}{c}\text { Eigen } \\
\text { value }\end{array}$ & $\begin{array}{c}\text { \% Total } \\
\text { variance }\end{array}$ & $\begin{array}{c}\text { Cumulative } \\
\text { Eigen value }\end{array}$ & $\begin{array}{c}\text { Cumulative } \\
\text { \% }\end{array}$ \\
\hline $\mathrm{TF}_{\mathrm{HPLC}}$ & 2.239 & 55.991 & 2.239 & 55.991 \\
Sum GF & 1.688 & 42.203 & 3.927 & 98.194 \\
Sum MF & 0.067 & 1.685 & 3.995 & 99.880 \\
TEAC & 0.005 & 0.119 & 4.000 & 100.000 \\
\hline
\end{tabular}

$\mathrm{TF}_{\mathrm{HPLC}}$ : sum of total flavonoids determined by HPLC, Sum GF: sum of glycosylated flavanones, Sum MF: sum of polymethoxylated flavones, TEAC: Trolox Equivalent Antioxidant Capacity.

\section{CONCLUSION}

The main flavonoids of Maltease orange peel are glycosylated flavanones (neohesperidin, hesperidin, narirutin, naringin, didymin, eriocitrin) and polymethoxylated flavones (sinensetin, tangeretin, nobiletin, hexamethoxyflavone). Interestingly, neohesperidin and hesperidin were the main flavonoids constituent of the peel $(87.69 \%$ of total flavonoids).This study is the first report comparing the efficiency of four extraction methods of Maltease orange peel phenolic compounds in terms of total and individual flavonoids and their antioxidant activities. MAE (80\% ethanol, m/v: $5 \mathrm{~g}, 50 \mathrm{ml}, 170 \mathrm{~W}$ for $10 \mathrm{~s}$, and 3 successive extractions) was found to be the better extraction method for total and individual flavonoid than ultrasound assisted extraction, conventional solvent extraction, and supercritical $\mathrm{CO}_{2}$ extraction. Whereas, the CSE method gives the highest radical scavenging activity. MAE showed many advantages, such as shorter time, higher extraction rate, the saving of energy and better products with lower cost compared to supercritical $\mathrm{CO}_{2}$ extraction. This study showed also that there is no additivity on antioxidant activity. Consequently, the antioxidant activity of orange peel extract can be due to the synergic effect between flavonoids but also with others compounds of the extract such as vitamin C. Moreover, interactions between flavonoids or degradation products occur and can lead to positive or negative synergies on the antioxidant activity. 


\section{ACKNOWLEDGEMENT}

This work was financially supported by the Tunisian Ministry of Higher Education and Scientific Research. The authors thank Pr. Danielle BARTH (ENSIC, LRGP, Nancy, France).

Conflict of Interests: There are no conflicts of interest.

\section{REFERENCES}

Anagnostopoulou MA, Kefalas P, Kokkalou E, Assimopoulou AN, Papageorgiou FP. Analysis of antioxidant compounds in sweet orange peel by HPLC-diode array detection-electrospray ionization mass spectrometry. Biomed Chromatogr, 2005; 1: 138-148.

Aspé E, Fernández K. The effect of different extraction techniques on extraction yield, total phenolic, and anti-radical capacity of extracts from Pinus radiate Bark. Ind Crops Prod, 2011; 34: 838-844.

Bairy PS, Bora NS, Kakoti BB, Das A, Nainwal LM, Gogoi B. Preliminary phytochemical screening, in vitro antioxidant activity, total polyphenolic and flavonoid content of Garcinia lanceifolia Roxb. and Citrus maxima (Burm.) Merr. J App Pharm Sci, 2016; 6 (9) : 133-139.

Bampidis VA, Robinson PH. Citrus by-products as ruminant feeds: a review. Anim Feed Sci Tech, 2006; 128: 175-217.

Berim A, Gang DR. Methoxylated flavones: occurrence, importance, biosynthesis. Phytochem Rev, 2015. DOI 10.1007/s11101$015-9426-0$

Bocco A, Cuvelier ME, Richard H, Berset C. Antioxidant activity and phenolic composition of citrus peel and seed extracts. J Agric Food Chem, 1998; 46 (6): 2123-2129.

Boukroufa M, Boutekedjiret C, Petigny L, Rakotomanomana N, Chemat F. Bio-refinery of orange peels waste: A new concept based on integrated green and solvent free extraction processes using ultrasound and microwave techniques to obtain essential oil, polyphenols and pectin. Ultrason. Sonochem, 2015; 24: 72-79.

Burda S, Oleszek W. Antioxidant and antiradical activities of flavonoids. J Agric Food Chem, 2001; 49: 2774-2779.

Chemat F, Abert-Vian M, Zill-e-Huma. Microwave assistedseparations: green chemistry in action. In: Pearlman, J.T. (Ed.), Green Chemistry Research Trends, 2009, Nova Science Publishers Inc., United States: 1-30.

Chemat F, Huma Z, Khan MK. Applications of ultrasound in food technology: Processing, preservation and extraction. Ultrason Sonochem, 2011; 18: 813-835.

Chen ML, Yang DJ, Liu SC. Effects of drying temperature on the flavonoid, phenolic acid and antioxidative capacities of the methanol extract of citrus fruit (Citrus sinensis (L.) Osbeck) peels. Int J Food Sci Tech, 2011; 46: 1179-1185.

Constantin RP, Bracht A, Yamamoto NS, Ishii-Iwamoto EL, Constantin J. Molecular mechanisms of citrus flavanones on hepatic gluconeogenesis. Fitoterapia, $2014 ; 92$ : 148-162.

Dahmoune F, Boulekbache L, Moussi K, Aoun O, Spigno G, Madani K. Valorization of citrus limon residues for the recovery of antioxidants: evaluation and optimization of microwave and ultrasound application to solvent extraction. Ind Crops Prod, 2013; 50: 77 87.

Diaaz-Reinoso B, Moure S, Domianguez H, Parajoa JC. Supercritical $\mathrm{CO}_{2}$ extraction and purification of compounds with antioxidant activity. J Agric Food Chem, 2006; 54: 2441-2469.

Ghanem N, Mihoubi D, Kechaoua N, BoudhriouaMihoubi N. Microwave dehydration of three citrus peel cultivars: Effect on water and oil retention capacities, color, shrinkage and total phenols content. Ind Crops Prod, 2012; 40: 167-177.

Ghasemi K, Ghasemi Y, Ebrahim Zadeh MA. Antioxidant activity, phenol and flavonoid contents of 13 citrus species peels and tissues. Pak Pharm Sci, 2009; 22 (3): 277-281.
Gil-Chavez GJ, Villa JA, Ayala-Zavala JF, Heredia JB, Sepulveda D, Yahia EM, Gonzalez-Aguilar GA. Technologies for Extraction and Production of Bioactive Compounds to be used as Nutraceuticals and Food Ingredients: An Overview. Compr Rev Food Sci F, 2013; 12: 5-19.

Goulas V, Manganaris GA. Exploring the phytochemical content and the antioxidant potential of Citrus fruits grown in Cyprus. Food Chem, 2012; 131: 39-47.

Hayat K, Hussain S, Abbas S, Farooq U, Ding B, Xia S, Ji C, Zhang X, Xia W. Optimized microwave-assisted extraction of phenolic acids from citrus mandarin peels and evaluation of antioxidant activity in vitro. Sep PurifTechnol, 2009; 70: 63-70.

Hayat K, Zhang X, Chen H, Xi S, Jia C, Zhong F. Liberation and separation of phenolic compounds from citrus mandarin peels by microwave heating and its effect on antioxidant activity. Sep Purif Technol, 2010; 73: 371-376.

Hidalgo M, Sánchez-Moreno C, De Pascual-Teresa S. Flavonoid interaction and its effect on their antioxidant activity. Food Chem, 2010; 121: 691-696.

Hodge J. Dehydrated foods-chemistry of browning reactions in model systems. J Agric Food Chem, 1953; 1 (15): 928-943.

Ioannou I, Hafsa I, Hamdi S, Charbonnel C, Ghoul M. Review of the effects of food processing and formulation on flavonol and anthocyanin behavior. J Food Eng, 2012; 111: 208-217.

Jawad A, Langrish TAG. Optimisation of total phenolic acids extraction from mandarin peels using microwave energy: The importance of the Maillard reaction. J Food Eng, 2012;109: 162-174.

Kammoun Bejar A, Ghanem N, Mihoubi D, Kechaou N, BoudhriouaMihoubi N. Effect of Infrared Drying on Drying Kinetics, Color, Total Phenols and Water and Oil Holding Capacities of Orange (Citrus Sinensis) Peel and Leaves. J Food Eng, 2011; 7 (5): 125 .

Kanaze FI, Termentzi A, Gabrieli C, Niopas I, Georgarakis M, Kokkaloua E. The phytochemical analysis and antioxidant activity assessment of orange peel (Citrus sinensis) cultivated in Greece-Crete indicates a new commercial source of hesperidin. Biomed Chromatogr, 2008, 23: 239-249.

Khan MK, Abert-Vian, M, Fabiano-Tixier AS, Dangles O, Chemat F. Ultrasound-assisted extraction of polyphenols (flavanone glycosides) from orange (Citrus sinensisL.) peel. Food Chem, 2010; 119: 851-858.

Konan MK, Koffi EN, Cisse I, Adima AA, BekroYA. Phytochemical, nutritional and antioxidant capacity of five Ivorian edible leaves aqueous extracts. J App Pharm Sci, 2016 ; 6 (9) : 082-086.

Li BB, Smith B, Hossain MM. Extraction of phenolics from citrus peels. I. Solvent extraction method. Sep Purif Technol, 2006; 48: 182-188.

Li W, Wang Z, Wang YP, Qun Liu CJ, Sun YS, Zheng YN. Pressurised liquid extraction combining LC-DAD-ESI/MS analysis as an alternative method to extract three major flavones in Citrus reticulata 'Chachi' (Guangchenpi). Food Chem, 2012; 130: 1044-1049.

Liu L, Fishman ML, Kost J, Hicks KB. Pectin-based systems for colon-specific drug delivery via oral route. Biomaterials, 2003; 24 3333-3343.

Liu SC, Yang DJ, Jin SY, Hsu CH, Chen SL. Kinetics of color development, $\mathrm{pH}$ decreasing, and anti-oxidative activity reduction of Maillard reaction in galactose/glycine model systems. Food Chem, 2008; 108 (2): 533-541.

M'hiri N, Ioannou I, Ghoul M, Mihoubi Boudhrioua N. Extraction methods of citrus peel phenolic compounds: a review. Food Rev Int, 2014; 30: 265-290. DOI: 10.1080/87559129.2014.924139.

M'hiri N, Ioannou I, MihoubiBoudhrioua N, Ghoul M. Effect of different operating conditions on the extraction of phenolic compounds in orange peel . Food Bioprod Process, 2015, 96 : 161-170.

Mahmoud AM, Ashour MB, Abdel-Moneim A, Ahmed OM. Hesperidin and naringin attenuate hyperglycemia-mediated oxidative stress and proinflammatory cytokine production in high fat 
fed/streptozotocin-induced type 2 diabetic rats. J Diabetes Complications, 2012 ; 26 483-490.

Mandal V, Mohan Y, Hemalatha S. Microwave assisted extraction-An innovative and promising extraction tool for medicinal plant research. Pharmacogn Rev, 2007; 1: 7-18.

Manthey JA, Grohmann K. Concentrations of hesperidin and other orange peel flavonoids in citrus processing byproducts. J Agric Food Chem, 1996; 44: 811-814.

Mason T, Chemat F, Vinatoru M. The extraction of natural products using ultrasound and microwaves. Curr. Org. Chem, 2011; 15: 237-247.

Nayak B, Liu RH, Tang J. Effect of Processing on Phenolic Antioxidants of Fruits, Vegetables, and Grains-A Review. Crit Rev Food SciNutr, 2015a; 55: 887-918.

Nayak B, Dahmoune F, Moussi K, Remini H, Dairi S, Aoun O, Khodir M. Comparison of microwave, ultrasound and accelerated-assisted solvent extraction for recovery of polyphenols from Citrus sinensis peels. Food Chem, 2015b; 187: 507-516

Neveu V, Perez-Jimenez J, Vos F, Crespy V, Du Chaffaut L, Mennen L, Knox C, Eisner R, Cruz J, Wishart D, Scalbert A. PhenolExplorer: an online comprehensive database on polyphenol contents in foods. Database, 2010; 1-9. doi:10.1093/database/bap024

Nicoli MC, Anese M, Severini C. Combined effects in preventing enzymatic browning reactions in minimally processed fruit. $\mathrm{J}$ Food Qual, 1994; 17: 221-229.

Park HJ, Jung UJ, Cho SJ, Jung HK, Shim S, Choi, MS. Citrus unshiu peel extract ameliorates hyperglycemia and hepatic steatosis by altering inflammation and hepatic glucose- and lipid-regulating enzymes in db/dbmice. J Nutr Biochem, 2013; 24 : 419-427.

Pereira CG, Meireles MAA. Supercritical Fluid Extraction of Bioactive Compounds: Fundamentals, Applications and Economic Perspectives. Food Bioprocess Tech, 2010; 3: 340-372.

Pingret D, Fabiano-Tixier AS, Chemat F. Degradation during application of ultrasound in food processing: A review. Food Control, 2013; 31: 593-606.

Pingret D, Fabiano-Tixier AS, Petitcolas E, Canselier JP, Chemat F. First investigation on ultrasound-assisted preparation of food products: sensory and physicochemical characteristics. J Food Sci, 2012; 76: $287-292$

Piriyaprasarth S, Sriamornsak P. Flocculating and suspending properties of commercial citrus pectin and pectin extracted from pomelo (Citrus maxima) peel. Carbohydr Polym, 2011; 83 (2): 561-568.

Rao AL, BharaniM.Pallavi V. Role of antioxidants and free radicals in health and disease, AdvPharmacolToxicol.2006; 7: 29-38.

Rawson A, Patras A, Tiwari BK, Noci F, Koutchma T, Brunton $\mathrm{N}$. Effect of thermal and non thermal processing technologies on the bioactive content of exotic fruits and their products: Review of recent advances. Food Res Int, 2011; 44 (7): 1875-1887.

Reber JD, Eggett DL, Parker TL. Antioxidant capacity interactions and a chemical/structural model of phenolic compounds found in strawberries.Int J Food SciNutr, 2011;62: 445-452.

Rice-Evans C, Miller N, Paganga G. Structure-antioxidant activity relationships between flavonoids and phenolic acids. Free RadicBiol Med, 1996; 20: 933-956.

Rombaut N, Tixier AS, Bily A, Chemat F. Green extraction processes of natural products as tools for biorefinery. Biofuels, BioprodBiorefin, 2014;8: 530-544.
Saito T, Abe D, Nogata Y. Polymethoxylated flavones potentiate the cytolytic activity of NK leukimia cell line KHYG-1 via enhanced expression of granzyme B. Biochem Biophys Res Commun, 2015; 456:799-803.

Singleton VL, Orthofer R, Lamuela-Raventos RM. Analysis of total phenols and other oxidation substrates and antioxidants by means of folin-ciocalteu reagent. Methods Enzymol, 1988; 299: 152-178.

Sultana B, Anwar F, Asi MR, Chatha SAS. Antioxidant potential of extracts from different agro wastes: Stabilization of corn oil. Grasas y Aceites, 2008; 59 (3): 205-217.

Tabart J, Kevers C, Pincemail J, Defraigne JO, Dommes J. Evaluation of spectrometric methods for antioxidant compound measurement in relation to total antioxidant capacity in beverages. Food Chem, 2010;120: 607- 614.

Toledo-Guillén AR, Higuera-Ciapara I, García-Navarrete G, De la Fuente JC. Extraction of bioactive flavonoid compounds from orange (Citrus sinensis) peel using supercritical $\mathrm{CO}_{2}$. J Biotechnol, 2010: 150576.

Vinayagam R, Xu B. Antidiabetic properties of dietary flavonoids: a cellular mechanism review. Nutrition \& Metabolism, 2015: $12(60): 1-20$

Wagner KH, Derkits S, Herr M., Schuh W, Elmadfa I. Antioxidative potential of melanoidins isolated from a roasted glucoseglycine model. Food Chem, 2002; 78 (3): 375-382.

Wang S, Chen P, Jiang W, Wu L, Chen L, Fan X, Wang Y, Cheng Y. Identification of the effective constituents for anti-inflammatory activity of Ju-Zhi-Jiang-Tang, an ancient traditional Chinese medicine formula. J Chromatogr, $2014 ; 1348: 105-124$.

Wang, AY, Zhou MY, Lin WC.Antioxidative and antiinflammatory properties of Citrus sulcata extracts. Food Chem, 2011; 124 958-963.

Xu JJ, Wu X, Li MM, Li GQ, Yang YT, Luo HJ, Huang WH, Chung HY, Ye WC, Wang GC, Li YL. Antiviral activity of polymethoxylated flavones from "Guangchenpi", the edible and medicinal pericarps of Citrus reticulata 'Chachii'. J Agric Food Chem, 2014 ; 62: 2182-2189

Yaylayan VA, Haffenden LJW. Mechanism of imidazole and oxazole formation in c-13-2-labelled glycine and alanine model systems. Food Chem, 2003; 81 (3): 403-409.

Zhishen J, Mengcheng T, Jiamming W. The determination of flavonoid contents in mulberry and their scavenging effect on superoxide radicals. Food Chem, 1999; 64: 555-559.

\section{How to cite this article:}

M'hiri N, Irina I, Cédric P, Ghoul M, Boudhrioua N. Antioxidants of Maltease orange peel: comparative investigation of the efficiency of four extraction methods. J App Pharm Sci, 2017; 7 (11): 126-135. 